\title{
Investigations of thiol-modified phenol derivatives for the use in thiol-ene photopolymerizations
}

\author{
Sebastian Reinelt ${ }^{1}$, Monir Tabatabai ${ }^{1}$, Urs Karl Fischer ${ }^{2}$, Norbert Moszner ${ }^{2}$, \\ Andreas Utterodt ${ }^{3}$ and Helmut Ritter ${ }^{* 1}$
}

Open Access

\author{
Full Research Paper \\ Address: \\ ${ }^{1}$ Heinrich-Heine-University Düsseldorf, Institute of Organic Chemistry \\ and Macromolecular Chemistry, Department of Preparative Polymer \\ Chemistry, Universitätsstraße 1, 40225 Düsseldorf, Germany, ${ }^{2}$ Ivoclar \\ Vivadent AG, Bendererstrasse 2, 9494 Schaan, Principality of \\ Liechtenstein and ${ }^{3}$ Heraeus Kulzer $\mathrm{GmbH}$, Philipp-Reis-Straße 8, \\ 61273 Wehrheim, Germany

\section{Email:} \\ Helmut Ritter ${ }^{*}$ - h.ritter@uni-duesseldorf.de \\ * Corresponding author

\section{Keywords:} \\ composites; crosslinking; dental polymers; high performance \\ polymers; photopolymerization
}

Beilstein J. Org. Chem. 2014, 10, 1733-1740.

doi:10.3762/bjoc. 10.180

Received: 24 March 2014

Accepted: 01 July 2014

Published: 29 July 2014

Associate Editor: P. J. Skabara

(c) 2014 Reinelt et al; licensee Beilstein-Institut. License and terms: see end of document.

\begin{abstract}
Thiol-ene photopolymerizations gain a growing interest in academic research. Coatings and dental restoratives are interesting applications for thiol-ene photopolymerizations due to their unique features. In most studies the relative flexible and hydrophilic ester derivative, namely pentaerythritoltetra(3-mercaptopropionate) (PETMP), is investigated as the thiol component. Thus, in the present study we are encouraged to investigate the performance of more hydrophobic ester-free thiol-modified bis- and trisphenol derivatives in thiol-ene photopolymerizations. For this, six different thiol-modified bis- and trisphenol derivatives exhibiting four to six thiol groups are synthesized via the radical addition of thioacetic acid to suitable allyl-modified precursors and subsequent hydrolysis. Compared to PETMP better flexural strength and modulus of elasticity are achievable in thiol-ene photopolymerizations employing 1,3,5-triallyl-1,3,5-triazine-2,4,6-trione (TATATO) as the ene derivative. Especially, after storage in water, the flexural strength and modulus of elasticity is twice as high compared to the PETMP reference system.
\end{abstract}

\section{Introduction}

Restorative composites consist of a polymerizable organic matrix (10-60 wt \%) and inorganic fillers (40-90 wt \%) [1]. Up to date, 2,2-bis(4-(2-hydroxy-3-methacryloxyprop-1-oxy)phenyl)propane (Bis-GMA), 1,6-bis(methacryloxy-2-ethoxycarbonylamino)-(mixture of 2,2,4 and 2,4,4)-trimethylhexane (UDMA) and triethylene glycol dimethacrylate (TEGDMA) are still the dominating monomers of the organic matrix used in the formulation of dental composites [1-4].

The shrinkage stress and the leachability of unreacted monomers due to an insufficient double bond conversion are two of the main drawbacks of dimethacrylate based dental 
resins and are still a driving force for dental researches [2]. Many efforts have been undertaken in the last decades aiming to face and overcome these limitations [1,4-8]. For instance the design of tailored (meth)acrylates based on calix[4]arenes $[9,10]$ or tricyclodecane $[11,12]$ backbones and use of ringopening monomers as cyclopropane derivatives $[13,14]$, siloranes [15] or spiroorthocarbonates [16] are worth to be mentioned.

Since Sharpless et al. published their concept of click chemistry in 2001, these reactions gained growing impact on the design of new materials [17]. Besides the alkyne-azide reaction, especially thiol-ene reactions were studied extensively [18-21] Bowman and coworkers first investigated thiol-ene photopolymerizations as promising approach towards novel, lowshrinkage dental restoratives $[22,23]$. In contrast to the chaingrowth mechanism of dimethylacrylate-based systems thiol-ene polymerizations proceed via a step-growth mechanism [24] which offers the advantage of a delayed gel point and thus, a reduced shrinkage stress $[22,25]$. These preliminary studies were an offense for further investigations in the field of thiolbased materials covering the topics of ternary thiol-enemethacrylate system [26-28], adaptable thiol-ene networks [29], thiol-yne photopolymerizations [30-32], and thiol-norbornene materials [33] only to mention a few of them. However, the design of new monomers - both ene and thiol monomers - for thiol-ene polymerization is a sustained necessity in order to improve the mechanical properties of the resulting networks [34]. So far most studies focused on the optimization of the ene monomer while PETMP (pentaerythritol tetra(3-mercaptopropionate)) was constantly utilized as the thiol component.

The influence of water sorption of cured dental composites on the mechanical properties have been investigated and discussed extensively in several studies dealing with dimethacrylate based composites. The use of hydrophilic monomers leads to a higher water uptake which induces reduced strength, stiffness and wear-resistance and may cause erosion of the filler or of the unreacted monomer [35-38]. For studies focusing on thiol-ene photopolymerizations for dental restoratives, the mechanical properties of the cured composites are always determined under ambient conditions. However, the mainly investigated PETMP monomer has a partial hydrophilic character due to its four ester linkages and thus, a significant influence of water sorption on the mechanical properties should be expected.

The limited availability of rigid thiol monomers is the initial point for this study. In analogy to Bis-GMA which is a wellestablished monomer for dental materials exhibiting good mechanical properties based on its rigid structure, we wish to present the synthesis of various multifunctional, hydrophobic thiol monomers all having in common a rigid phenol backbone and at least four primary aliphatic groups as well as the fact that they are ester-free liquids. Their behavior in thiol-ene photopolymerizations regarding the conversion and mechanical properties before and after water storage is investigated and compared to the widely used PETMP. Thereby, the well-established, commercially available triallyl-1,3,5-triazine-2,4,6trione (TATATO) is utilized as the ene monomer.

\section{Results and Discussion}

Synthesis and characterization of the thiol-modified bis- and trisphenol derivatives. Most synthetic routes for the preparation of thiols make use of alkyl halogenide or allyl derivatives as suitable precursors which are subsequently converted into the corresponding thiols [39]. In the present study, the synthesis of the phenol-based thiols (10a,b, 14a-c, 17) was accomplished by the radical addition of thioacetic acid to suitable allyl-modified precursors as depicted in Scheme 1 and Scheme 2. For the synthesis of 10a and 10b the well-established hydroxymethylation of bisphenol A was the starting point of the reaction sequence and yielded compound $\mathbf{3}$. The quantitative etherification of the phenolic hydroxy groups with potassium carbonate and ethyl iodide yielded the corresponding ether derivative $\mathbf{5}$. Subsequently the remaining hydroxy groups of $\mathbf{3}$ and $\mathbf{5}$ were o-alkylated in the presence of a strong base such as sodium hydride and allyl bromide (6), which resulted in the formation of the tetra-allyl (7a) and hexa-allyl (7b) derivatives (Scheme 1).

The second route for the synthesis of the allyl-modified precursors $(\mathbf{1 2 a}-\mathbf{c}, \mathbf{1 5})$ proceeded via Claisen rearrangement of the allylaryl ethers and subsequent etherification, which was conducted in analogy to a procedure described in literature [40], as demonstrated in Scheme 2. Bisphenol A, bisphenol S and the trisphenol derivative 1,1,1-tris(4-hydroxyphenyl)ethane were chosen as basic structures. Subsequently, the successful radical addition of thioacetic acid (8) to the allyl-modified precursors (7a,b, 12a-c, 15) by use of 2,2'-azobis(2-methylpropionitrile) (AIBN) as the radical source was easily proven by the occurrence of the typical $\mathrm{C}=\mathrm{O}$ valence vibration of the thioester $(9 \mathbf{a}, \mathbf{b}, 13 \mathbf{a}-\mathbf{c}, \mathbf{1 6})$ in the corresponding FTIR spectra at $1684 \mathrm{~cm}^{-1}$ (Figure 1). Additionally, in the range of 6.2 to $4.9 \mathrm{ppm}$ signals corresponding with the presence of a double bond were no longer observed in the ${ }^{1} \mathrm{H}$ NMR spectra. Simultaneously, the appearance of a signal at 2.4 to $2.3 \mathrm{ppm}$ was observed, which corresponds with the methyl group of the thioester (see Figure 2).

The thioester derivatives 9a,b, 13a-c and $\mathbf{1 6}$ were successfully hydrolyzed under acidic conditions to obtain the thiols $\mathbf{1 0 a}, \mathbf{b}$, 14a-c and 17 as viscous oils. The corresponding FTIR spectra 


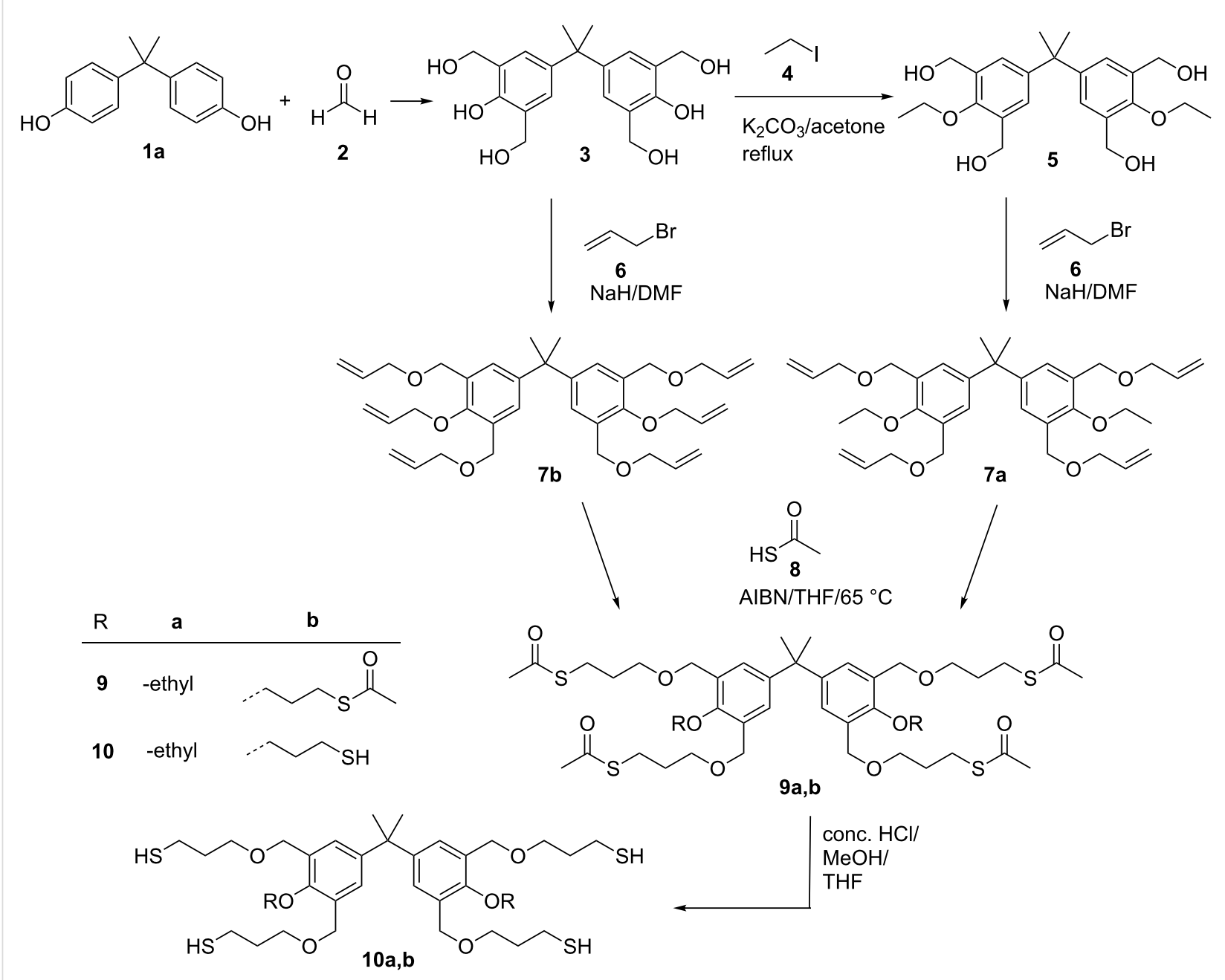

Scheme 1: Synthetic route for the preparation of the thiol-functionalized bisphenols $10 \mathrm{a}$ and $10 \mathrm{~b}$.

showed the disappearance of the strong $\mathrm{C}=\mathrm{O}$ valence vibration at $1684 \mathrm{~cm}^{-1}$ and the simultaneous appearance of the weak $\mathrm{S}-\mathrm{H}$ valence vibration at approximately $2560 \mathrm{~cm}^{-1}$. Exemplarily, Figure 1 shows a comparison of the FTIR spectra of compound 12b, 13b, and 14b. In Figure 2, a typical ${ }^{1} \mathrm{H}$ NMR spectrum of the thioester 13a and the thiol 14a is shown (further ${ }^{1} \mathrm{H}$ and ${ }^{13} \mathrm{C}$ NMR spectra of all thiols can be found in Supporting Information File 1). Besides FTIR, ${ }^{1} \mathrm{H}$ and ${ }^{13} \mathrm{C}$ NMR spectroscopy, elemental analysis and mass spectrometry was conducted for detailed characterization of all products $10 \mathbf{a}, \mathbf{b}, \mathbf{1 4 a}-\mathbf{c}$ and 17 .

Mechanical properties of 10a,b, 14a-c and 17 employed in thiol-ene photopolymerizations. In this study we measured the flexural strength, flexural modulus of elasticity and the conversion of unfilled thiol-ene samples containing thiol compounds 10a,b, 14a-c and $\mathbf{1 7}$ and TATATO (see Scheme 3) in stoichiometric amounts with respect to the functional groups. For evaluation of the mechanical performance of the phenol based thiols in photopolymerizations the widely used monomer PETMP was used as reference monomer [22,23,33]. As the initiating compound, the newly developed photoinitiator di(4methoxy)benzoyl(diethyl)germane (K69) was utilized since recent studies showed an excellent performance of K69 in dental materials compared to campherchinone/4-( $N, N$-dimethylamino)benzoate initiation [41].

As evident from Table 1, all investigated thiol derivatives (10b, 14a-c and 17) - except for monomer 10a - outperformed the reference monomer PETMP regarding flexural strength and flexural modulus of elasticity of the photopolymerized thiol-ene samples. For the derivatives with a propyl spacer, 14a-c and 17, the flexural strength varied between 121.8 MPa (14a) and 112.7 MPa (17) compared to 109.3 MPa for PETMP. For the samples containing $\mathbf{1 4 a - c}$ and $\mathbf{1 7}$ no change in the flexural strength was observed after storing the samples in water for 24 hours at $37^{\circ} \mathrm{C}$. In contrast to that, the flexural strength of the 
A

$\overbrace{1 \mathrm{a}-\mathrm{c}}^{\mathrm{C}}+\overbrace{\mathrm{OH}}^{\mathrm{Br}}$

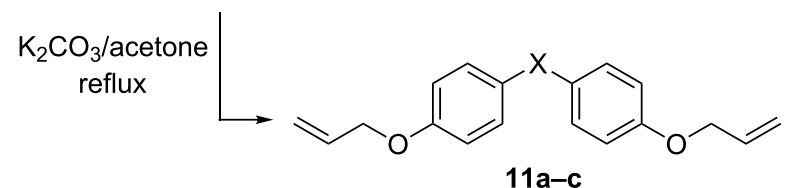

Substituent $X$ (compound no.)

$11 \mathrm{C}\left(\mathrm{CH}_{3}\right)_{2}(11 \mathrm{a}) \quad \mathrm{SO}_{2}(11 \mathrm{~b})$<smiles>CCCOc1ccc(C)cc1</smiles>

(11c)

$12 \mathrm{C}\left(\mathrm{CH}_{3}\right)_{2}(12 \mathrm{a}) \quad \mathrm{SO}_{2}(12 \mathrm{~b})$<smiles>C=CCOc1ccc(C(C)(C)C)cc1CC=C</smiles>

(12c)

$13 \mathrm{C}\left(\mathrm{CH}_{3}\right)_{2}(13 a) \quad \mathrm{SO}_{2}(13 \mathrm{~b})$<smiles>CC(=O)SCCCOc1ccc(C(C)(C)C)cc1CCCSC(C)=O</smiles>

1. $220^{\circ} \mathrm{C}, 4 \mathrm{~h}$

2. $6 / \mathrm{K}_{2} \mathrm{CO}_{3}$ /acetone

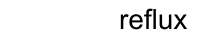<smiles>[R10]CCOc1ccc([X])cc1CC=C</smiles>

$12 a-c$
$\mathrm{HS}_{8}^{\mathrm{O}}$

AIBN/THF $/ 65^{\circ} \mathrm{C}$<smiles></smiles><smiles>CC(C)C</smiles>

$14 a-c$

(14c)

B<smiles>C=CCOc1ccc(C(C)(C)c2ccc(OCC=C)c(CC=C)c2)cc1CC=C</smiles>

$12 a$

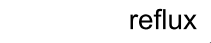<smiles>C=CCOc1c(CC=C)cc(C(C)(C)c2cc(CC=C)c(OCC=C)c(CC=C)c2)cc1CC=C</smiles><smiles>CC(=O)SCCCOc1c(CCCSC(C)=O)cc(C(C)(C)c2cc(CCCSC(C)=O)c(OCCCSC(C)=O)c(CCCSC(C)=O)c2)cc1CCCSC(C)=O</smiles><smiles>CC(=O)OC(C)(F)Cl</smiles><smiles>CC(C)(c1cc(CCCS)c(OCCCS)c(CCCS)c1)c1cc(CCCS)c(OCCCS)c(CCCS)c1</smiles>

Scheme 2: Synthetic route for the preparation of thiol-functionalized phenol derivatives $14 a-c$ and 17 using the Claisen rearrangement and the radical addition of thioacetic acid as key steps.

PETMP containing sample decreased by $50 \%$ to a value of $47.8 \mathrm{MPa}$. Similar results were found for the modulus of elasticity: the PETMP sample showed a decrease from $3.2 \mathrm{GPa}$ to
1.0 GPa after storage in water, whereas for $14 \mathbf{a}-\mathbf{c}$ and 17 values between 3.0 GPa and 2.8 GPa were found that slightly decreased to $2.8 \mathrm{GPa}$ and $2.7 \mathrm{GPa}$ after storage in water. Thus, as 


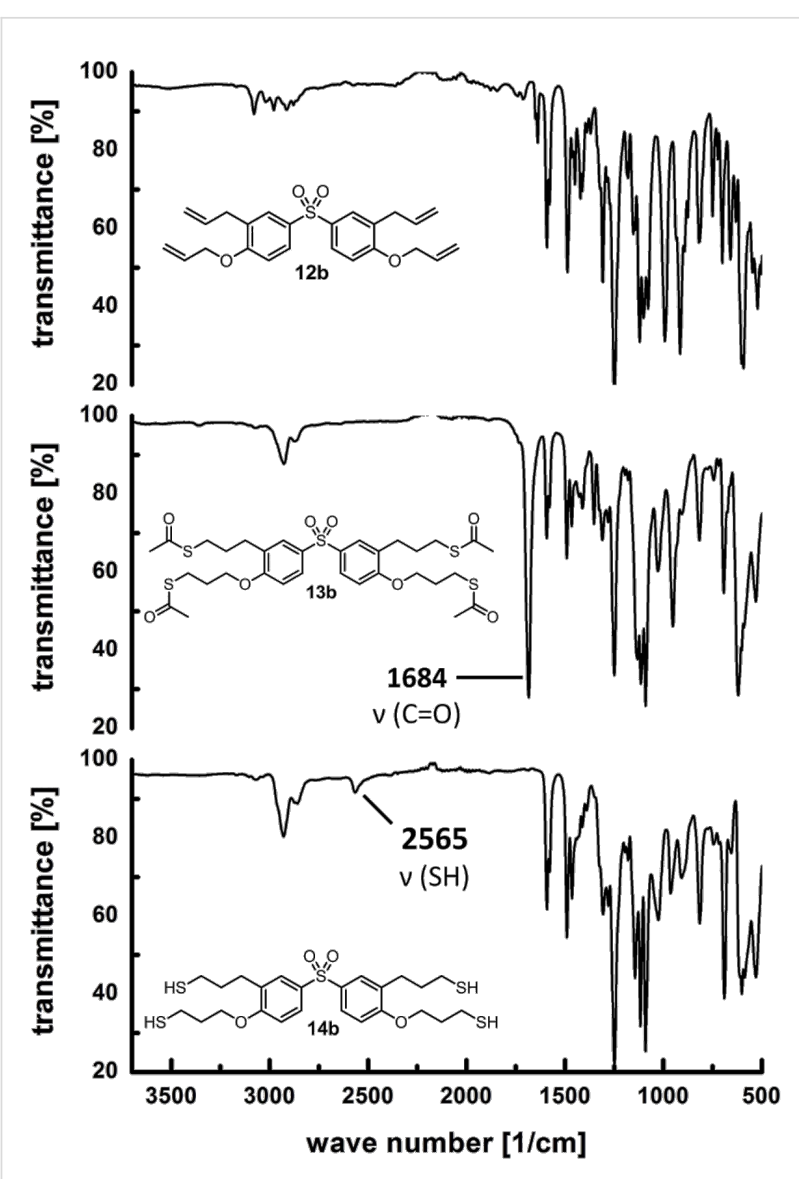

Figure 1: FTIR spectra of compounds $12 \mathrm{~b}, 13 \mathrm{~b}$ and $14 \mathrm{~b}$.

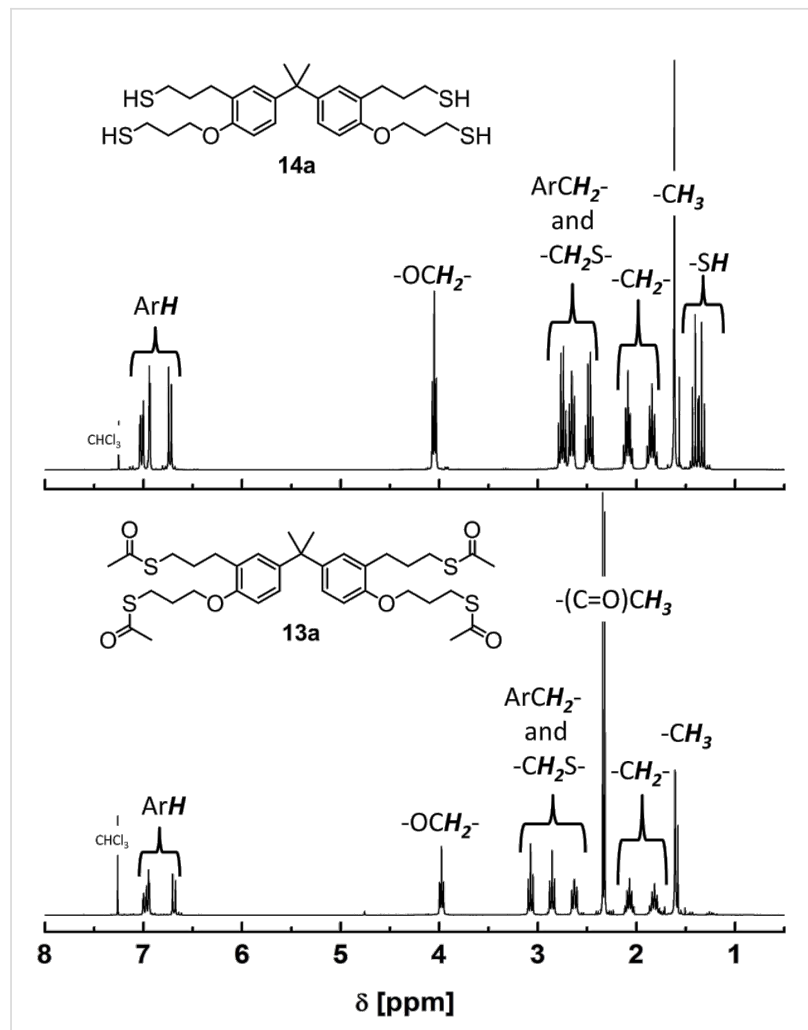

Figure 2: Top: ${ }^{1} \mathrm{H}$ NMR spectrum of 3,3'-(propane-2,2-diylbis(2-(3mercaptopropoxy)-5,1-phenylene))bis(propane-1-thiol) (14a) in $\mathrm{CDCl}_{3}$ (300 MHz, rt); bottom: ${ }^{1} \mathrm{H}$ NMR spectrum of $S, S^{\prime}-(($ propane-2,2diylbis(2-(3-(acetylthio)propoxy)-5,1-phenylene))bis(propane-3,1-diyl)) diethanethioate (13a) in $\mathrm{CDCl}_{3}(300 \mathrm{MHz}, \mathrm{rt})$.

and 17. Regarding 14a and 14b, no significant effect was found by changing the backbone from bisphenol A to bisphenol $\mathrm{S}$. Monomer 10a, incorporating four thiol-groups with a longer, more flexible and hydrophilic methoxypropyl spacer showed a significantly lower flexural strength of 29.1 MPa, and 9.1 MPa after water storage. For the flexural modulus values of $0.4 \mathrm{GPa}$ and $0.1 \mathrm{GPa}$, respectively, were found. The introduction of two

Table 1: Flexural strength and flexural modulus of elasticity before and after storage in $\mathrm{H}_{2} \mathrm{O}$ as well as the conversion. All samples contained a stoichiometric amount of TATATO and the below-mentioned thiol, $0.5 \mathrm{wt} \%$ initiator (K69) and 0.04 wt \% Q1301.

\begin{tabular}{|c|c|c|c|c|c|c|}
\hline \multirow{2}{*}{ Thiol } & \multicolumn{2}{|c|}{$\begin{array}{l}\text { Flexural strength } \\
{[\mathrm{MPa}]}\end{array}$} & \multicolumn{2}{|c|}{$\begin{array}{l}\text { Flexural modulus of elasiticity } \\
\qquad[\mathrm{GPa}]\end{array}$} & \multicolumn{2}{|c|}{$\begin{array}{c}\text { Conversion } \\
{[\%]}\end{array}$} \\
\hline & $24 \mathrm{~h} \mathrm{rt}$ & $24 \mathrm{~h} \mathrm{H}_{2} \mathrm{O}$ & $24 \mathrm{~h} \mathrm{rt}$ & $24 \mathrm{~h} \mathrm{H}_{2} \mathrm{O}$ & Thiol & Ene \\
\hline PETMP & $109.3 \pm 2.6$ & $47.8 \pm 3.6$ & $3.2 \pm 0.2$ & $1.0 \pm 0.2$ & $89.2 \pm 4.2$ & $83.9 \pm 0.9$ \\
\hline $10 a$ & $29.1 \pm 1.5$ & $9.1 \pm 0.8$ & $0.4 \pm 0.1$ & $0.1 \pm 0.02$ & $97.2 \pm 4.8$ & $87.2 \pm 3.0$ \\
\hline $10 \mathrm{~b}$ & $98.4 \pm 8.5$ & $87.9 \pm 5.7$ & $3.0 \pm 0.2$ & $2.6 \pm 0.3$ & $81.9 \pm 1.7$ & $83.9 \pm 2.5$ \\
\hline $14 a$ & $121.8 \pm 3.4$ & $120.1 \pm 2.8$ & $3.0 \pm 0.2$ & $2.9 \pm 0.2$ & $66.4 \pm 2.7$ & $93.5 \pm 2.0$ \\
\hline $14 b$ & $133.6 \pm 6.4$ & $132.2 \pm 6.7$ & $2.8 \pm 0.2$ & $2.9 \pm 0.3$ & $71.4 \pm 2.0$ & $61.9 \pm 0.8$ \\
\hline $14 c$ & $127.8 \pm 6.2$ & $125 \pm 12.0$ & $3.0 \pm 0.2$ & $2.9 \pm 0.2$ & $68.2 \pm 1.8$ & $79.0 \pm 1.0$ \\
\hline 17 & $112.7 \pm 3.1$ & $119.4 \pm 3.6$ & $2.9 \pm 0.2$ & $2.7 \pm 0.1$ & $76.2 \pm 0.9$ & $82.6 \pm 0.8$ \\
\hline
\end{tabular}


<smiles>CCOc1c(COCCCS)cc(C(C)(C)c2cc(COCCCS)c(OCC)c(COCCCS)c2)cc1COCCCS</smiles>

$10 \mathrm{a}$<smiles>CC(C)(c1ccc(OCCCS)c(CCCS)c1)c1ccc(OCCCS)c(CCCS)c1</smiles>

$14 a$<smiles>CC(C)(c1cc(COCCCS)c(OCCCS)c(COCCCS)c1)c1cc(COCCCS)c(OCCCS)c(COCCCS)c1</smiles><smiles>O=S(=O)(c1ccc(OCCCS)c(CCCS)c1)c1ccc(OCCCS)c(CCCS)c1</smiles>

$14 b$<smiles>CC(c1ccc(OCCCS)c(CCCS)c1)(c1ccc(OCCCS)c(CCCS)c1)c1ccc(OCCCS)c(CCCS)c1</smiles><smiles>CC(C)(c1cc(CCCS)c(OCCCS)c(CCCS)c1)c1cc(CCCS)c(OCCCS)c(CCCS)c1</smiles><smiles>O=C(CCS)OCC(COC(=O)CCS)(COC(=O)CCS)COC(=O)CCS</smiles>

PETMP<smiles>C=CCn1c(=O)n(CC=C)c(=O)n(CC=C)c1=O</smiles>

TATATO

Scheme 3: Chemical structures of components utilized in the present study.

additional thiol groups in $\mathbf{1 0 b}$ compared to $\mathbf{1 0 a}$ improved the mechanical properties significantly.

Additionally, the performance of derivative $\mathbf{1 7}$ in a dental composite containing a stoichiometric amount with respect to the functional groups of TATATO was investigated and compared to a reference system containing PETMP/TATATO. The samples were prepared with a filler content of $59.98 \mathrm{wt} \%$, an initiator content of $0.2 \mathrm{wt} \%$ and $0.02 \mathrm{wt} \%$ inhibitor. The experimental results are summarized in Table 2. For the

Table 2: Flexural strength and modulus of elasticity before and after storage in $\mathrm{H}_{2} \mathrm{O}$, shrinkage force, exothermic setting time and exothermic setting temperature of dental composites containing $39.8 \mathrm{wt} \%$ organic matrix based on stoichiometric amounts of TATATO and the thiol component (PETMP respectively 17), $59.98 \mathrm{wt} \%$ inorganic filler, $0.20 \mathrm{wt} \%$ initiator (K69) and $0.02 \mathrm{wt} \%$ Q1301.

\begin{tabular}{|c|c|c|c|c|c|}
\hline Thiol & $\begin{array}{c}\text { Flexural strength } 24 \mathrm{~h} \\
\mathrm{rt} ;\left(24 \mathrm{~h} \mathrm{H}_{2} \mathrm{O}\right)[\mathrm{MPa}]\end{array}$ & $\begin{array}{l}\text { Flexural modulus of } \\
\text { elasticity } 24 \mathrm{~h} \mathrm{rt} ; \\
\left(24 \mathrm{~h} \mathrm{H}_{2} \mathrm{O}\right) \text { [GPa] }\end{array}$ & $\begin{array}{l}\text { Shrinkage force } \\
{[\mathrm{N}]}\end{array}$ & $\begin{array}{l}\text { Exothermic setting } \\
\text { temperature }\left(T_{\mathrm{s}}\right)^{\mathrm{a}}\left[{ }^{\circ} \mathrm{C}\right]\end{array}$ & $\begin{array}{l}\text { Exothermic setting } \\
\text { time }\left(t_{\mathrm{s}}\right)^{\mathrm{b}}[\mathrm{s}]\end{array}$ \\
\hline PETMP & $\begin{array}{l}86.9 \pm 7.6 \\
(61.9 \pm 5.7)\end{array}$ & $\begin{array}{l}4.9 \pm 0.2 \\
(2.2 \pm 0.2)\end{array}$ & $48.5 \pm 5.1$ & $17 \pm 2.1$ & $5.0 \pm 0.01$ \\
\hline 17 & $\begin{array}{l}101.5 \pm 5.8 \\
(97.0 \pm 6.4)\end{array}$ & $\begin{array}{l}5.1 \pm 0.1 \\
(4.2 \pm 0.2)\end{array}$ & $29.1 \pm 1.2$ & $13.7 \pm 0.4$ & $14.0 \pm 1.0$ \\
\hline
\end{tabular}

${ }^{a}$ Exothermic setting temperature is defined as the highest temperature reached during the curing process; ${ }^{b}$ exothermic setting time is defined as the time needed to reach the highest temperature. 
PETMP/TATATO system values for the flexural strength of 86.9 $\mathrm{MPa}$ and 61.9 $\mathrm{MPa}$ after storage in water while for the flexural modulus of $4.9 \mathrm{GPa}$ and $2.2 \mathrm{GPa}$ after storage in water were found. For the 17/TATATO system the flexural strength was found to be 101.5 MPa slightly decreasing to $97.0 \mathrm{MPa}$ after storage in water. The corresponding flexural modulus was determined to $5.1 \mathrm{GPa}$ and 4.2 GPa after storage in water. These results indicate that the mechanical properties of the composite containing $\mathbf{1 7}$ and TATATO as the organic matrix are higher than the reference system of PETMP/TATATO. Thus, after water storage the sample containing 17/TATATO showed significantly improved values for the flexural strength as well as for the flexural modulus. Additionally, the shrinkage force was measured using a Zwick UPM. For the sample containing 17/ TATATO the shrinkage force $(29.1 \mathrm{~N})$ was found to be $40 \%$ lower compared to the reference system PETMP/TATATO $(48.5 \mathrm{~N})$, although the mechanical properties were even better (see Table 2 and Figure 3). The exothermic temperature was comparable for both systems. In contrast the exothermic time was longer for the system 17/TATATO which indicates a slower polymerization kinetic (see Figure 3 ).

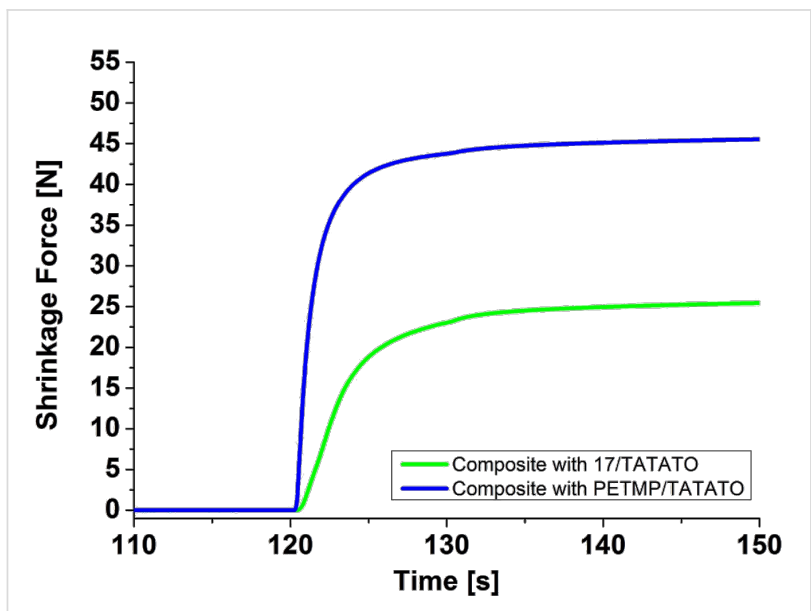

Figure 3: Development of the shrinkage force as function of time of dental composites containing $39.8 \mathrm{wt} \%$ organic matrix based stoichiometric amounts of TATATO and the thiol component (PETMP (blue line) or 17 (green line)), $59.98 \mathrm{wt} \%$ inorganic filler, $0.20 \mathrm{wt} \%$ initiator (K69) and $0.02 \mathrm{wt} \%$ Q1301. The exposure to light was initiated after $120 \mathrm{~s}$.

\section{Conclusion}

In the present study we successfully synthesized and evaluated thiol-modified bis- and trisphenol derivatives for photopolymerizations with TATATO serving as the ene monomer. In comparison to the widely used ester derivatives based on 3-mercaptopropionic acid the presented thiol derivatives were ester-free and thus, hydrolytically stable, so that they overcome one of the main drawbacks of established thiols. Four of the six synthesized thiol derivatives outperformed the standard thiol
PETMP regarding the flexural strength and flexural modulus of elasticity. To be utilizable for applications in dentistry, the mechanical performance after storage in water is of great importance. With respect to this aspect, the investigated thiols lead to an improvement of the flexural strength of up to $250 \%$ and up to $280 \%$ for the flexural modulus of elasticity compared to the initial values of the reference system PETMP/TATATO. Exemplarily, the performance of monomer 17 in a filled composite formulation was investigated and compared to a composite containing PETMP, still showing the excellent performance of the bisphenol monomer in matters of flexural strength, modulus of elasticity and shrinkage force.

\section{Supporting Information}

General descriptions of materials and methods, the syntheses of the obtained compounds $(\mathbf{5}, \mathbf{7 a}, \mathbf{b}, \mathbf{9 a}, \mathbf{b}, \mathbf{1 0 a}, \mathbf{b}$, 11a-c, 12a-c, 13a-c, 14a-c, 15, 16, 17) as well as analytical data $\left({ }^{1} \mathrm{H}\right.$ and ${ }^{13} \mathrm{C}$ NMR, FTIR and EIMS analyses) of these compounds and copies of ${ }^{1} \mathrm{H}$ and ${ }^{13} \mathrm{C}$ NMR spectra of compounds (10a,b, 14a-c, 17) plus the ${ }^{1} \mathrm{H}$ NMR spectra of compounds $(\mathbf{5}, 7 \mathbf{a}, 7 \mathbf{b}, \mathbf{9 a}, \mathbf{9 b}, \mathbf{1 2 c}$, 13a-c, 16) are given.

\section{Supporting Information File 1 \\ Experimental part. \\ [http://www.beilstein-journals.org/bjoc/content/ supplementary/1860-5397-10-180-S1.pdf]}

\section{References}

1. Moszner, N.; Hirt, T. J. Polym. Sci., Part A: Polym. Chem. 2012, 50, 4369-4402. doi:10.1002/pola.26260

2. Ferracane, J. L. Crit. Rev. Oral Biol. Med. 1995, 6, 302-318. doi:10.1177/10454411950060040301

3. Peutzfeldt, A. Eur. J. Oral Sci. 1997, 105, 97-116. doi:10.1111/j.1600-0722.1997.tb00188.x

4. Cramer, N.; Stansbury, J. W.; Bowman, C. N. J. Dent. Res. 2011, 90 , 402-416. doi:10.1177/0022034510381263

5. Braga, R. R.; Ferracane, J. L. Crit. Rev. Oral Biol. Med. 2004, 15, 176-184. doi:10.1177/154411130401500306

6. Moszner, N.; Salz, U. Prog. Polym. Sci. 2001, 26, 535-576. doi:10.1016/S0079-6700(01)00005-3

7. Lavigueur, C.; Zhu, X. X. RSC Adv. 2012, 2, 59-63. doi:10.1039/c1ra00922b

8. Moszner, N.; Salz, U. Macromol. Mater. Eng. 2007, 292, 245-271. doi:10.1002/mame.200600414

9. Tabatabai, M.; Garska, B.; Fischer, U.; Moszner, N.; Utterodt, A.; Ritter, H. Polym. Int. 2012, 61, 407-412. doi:10.1002/pi.3208

10. Moszner, N.; Ritter, H.; Fischer, U.-K.; Tabatabai, M.; Schaub, M.; Utterodt, A. Dental materials having low polymerization shrinkage. U.S Pat. Appl. US20080058443A1, March 6, 2008. 
11. Utterodt, A.; Ruppert, K.; Schaub, M.; Diefenbach, C.; Reischl, K.; Hohmann, A.; Eck, M.; Schoenhof, N. Compositions for dental composites with tricyclo[5.2.1.02.6]decane derivatives with decreased toxicity. U.S. Pat. Appl. US20100076115A1, March 25, 2010.

12. Utterodt, A.; Ruppert, K.; Schaub, M.; Diefenbach, C.; Reischl, K.; Hohmann, A.; Eck, M.; Schoenhof, N.; Schneider, J. Dental composite with low shrinkage tension and high flexural strength. Eur. Pat. Appl. EP2016931A2, Jan 21, 2009.

13. Moszner, N.; Zeuner, F.; Fischer, U. K.; Rheinberger, V.; de Meijere, A.; Bagutski, V. Macromol. Rapid Commun. 2003, 24 , 269-273. doi:10.1002/marc.200390040

14. Moszner, N.; Zeuner, F.; Völkel, T.; Rheinberger, V. Macromol. Chem. Phys. 1999, 200, 2173-2187. doi:10.1002/(SICI)1521-3935(19991001)200:10<2173::AID-MACP2173 $>3.0 . \mathrm{CO} ; 2-\mathrm{A}$

15. Weinmann, W.; Thalacker, C.; Guggenberger, R. Dent. Mater. 2005, 21, 68-74. doi:10.1016/j.dental.2004.10.007

16. Bailey, W. J. Polycyclic ring-opened polymers. U.S. Pat. Appl. US4387215A, June 7, 1983

17. Binder, W. H.; Sachsenhofer, R. Macromol. Rapid Commun. 2007, 28, 15-54. doi:10.1002/marc.200600625

18. Hoyle, C. E.; Lee, T. Y.; Roper, T. J. Polym. Sci., Part A: Polym. Chem. 2004, 42, 5301-5338. doi:10.1002/pola.20366

19. Hoyle, C. E.; Lowe, A. B.; Bowman, C. N. Chem. Soc. Rev. 2010, 39, 1355-1387. doi:10.1039/b901979k

20. Lowe, A. B. Polym. Chem. 2010, 1, 17-36. doi:10.1039/b9py00216b

21. Hoyle, C. E.; Bowman, C. N. Angew. Chem. 2010, 122, 1584-1617. doi:10.1002/ange.200903924

22. Lu, H.; Carioscia, J. A.; Stansbury, J. W.; Bowman, C. N. Dent. Mater. 2005, 21, 1129-1136. doi:10.1016/j.dental.2005.04.001

23. Carioscia, J. A.; Lu, H.; Stanbury, J. W.; Bowman, C. N. Dent. Mater. 2005, 21, 1137-1143. doi:10.1016/j.dental.2005.04.002

24. Kharasch, M. S.; Read, A. T.; Mayo, F. R. Chem. \& Ind. (London, U. K.) 1938, 752.

25. Chiou, B.-S.; Khan, S. A. Macromolecules 1997, 30, 7322-7328. doi:10.1021/ma9708656

26. Cramer, N. B.; Couch, C. L.; Schreck, K. M.; Carioscia, J. A.; Boulden, J. E.; Stansbury, J. W.; Bowman, C. N. Dent. Mater. 2010, 26, 21-28. doi:10.1016/j.dental.2009.08.004

27. Cramer, N. B.; Couch, C. L.; Schreck, K. M.; Boulden, J. E.; Wydra, R.; Stansbury, J. W.; Bowman, C. N. Dent. Mater. 2010, 26, 799-806. doi:10.1016/j.dental.2010.04.005

28. Boulden, J. E.; Cramer, N. B.; Schreck, K. M.; Couch, C. L.; Bracho-Troconis, C.; Stansbury, J. W.; Bowman, C. N. Dent. Mater. 2011, 27, 267-272. doi:10.1016/j.dental.2010.11.001

29. Kloxin, C. J.; Scott, T. F.; Bowman, C. N. Macromolecules 2009, 42, 2551-2556. doi:10.1021/ma802771b

30. Fairbanks, B. D.; Scott, T. F.; Kloxin, C. J.; Anseth, K. S.; Bowman, C. N. Macromolecules 2009, 42, 211-217. doi:10.1021/ma801903w

31. Fairbanks, B. D.; Sims, E. A.; Anseth, K. S.; Bowman, C. N. Macromolecules 2010, 43, 4113-4119. doi:10.1021/ma1002968

32. Chan, J. W.; Shin, J.; Hoyle, C. E.; Bowman, C. N.; Lowe, A. B. Macromolecules 2010, 43, 4937-4942. doi:10.1021/ma1004452

33. Carioscia, J. A.; Schneidewind, L.; O'Brien, C.; Ely, R.; Feeser, C.; Cramer, N.; Bowman, C. N. J. Polym. Sci., Part A: Polym. Chem. 2007, 45, 5686-5696. doi:10.1002/pola.22318

34. Lee, T. Y.; Smith, Z.; Reddy, S. K.; Cramer, N. B.; Bowman, C. N. Macromolecules 2007, 40, 1466-1472. doi:10.1021/ma062494b
35. Ferracane, J. L.; Hopkin, J. K.; Condon, J. R. Dent. Mater. 1995, 11 , 354-358. doi:10.1016/0109-5641(95)80034-4

36. Soderholm, K.-J. M.; Roberts, M. J. J. Dent. Res. 1990, 69, 1812-1816. doi:10.1177/00220345900690120501

37. Kawaguchi, M.; Fukushima, T.; Horibe, T. Dent. Mater. J. 1988, 7, 174-181. doi:10.4012/dmj.7.174

38. Ito, S.; Hashimoto, M.; Wadgaonkar, B.; Svizero, N.; Carvalho, R. M.; Yiu, C.; Rueggeberg, F. A.; Foulger, S.; Saito, T.; Nishitani, Y.; Yoshiyama, M.; Tay, F. R.; Pashley, D. H. Biomaterials 2005, 26, 6449-6459. doi:10.1016/j.biomaterials.2005.04.052

39. Patai, S. The chemistry of the thiol group; Wiley-VCH: Weinheim, Germany, 1974.

40. Herr, D. E.; Hallock, J. S. Photocurable composition based onacid functional primary resinous mercaptans. W.O. Pat. Appl. WO9858294A1, Dec 23, 1998.

41. Ganster, B.; Fischer, U. K.; Moszner, N.; Liska, R. Macromolecules 2008, 41, 2394-2400. doi:10.1021/ma702418q

\section{License and Terms}

This is an Open Access article under the terms of the Creative Commons Attribution License

(http://creativecommons.org/licenses/by/2.0), which permits unrestricted use, distribution, and reproduction in any medium, provided the original work is properly cited.

The license is subject to the Beilstein Journal of Organic Chemistry terms and conditions:

(http://www.beilstein-journals.org/bjoc)

The definitive version of this article is the electronic one which can be found at: doi:10.3762/bjoc. 10.180 